\title{
The High Impact of Education Abroad: College Students' Engagement in International Experiences and the Development of Intercultural Competencies
}

\section{Michael J. Stebleton}

University of Minnesota, Twin Cities

\section{Krista M. Soria}

University of Minnesota, Twin Cities

\section{Blythe T. Cherney}

University of Minnesota, Twin Cities

Study abroad opportunities continue to be a popular choice for U.S. college students looking to expand their undergraduate education. According to the recent figures released by the Open Doors Report on International Educational Exchange, approximately 273,996 U.S. students studied abroad for credit during the 2010-2011 academic year (Institute of International Education, 2012). Many of these students also opted to participate in work and/ or internship experiences. The Institute of International Education reported an increase of $7 \%$ in the number of students participating in practical work experiences included in their study abroad experience. Over 20,000 students received academic credit at U.S. colleges and universities for internships or work abroad. Despite a modest decline in the number of students studying abroad in recent years, campuses indicate that the number of students participating in study abroad is beginning to rebound, perhaps due to renewed student interest in global current events and the emphasis placed on gaining global and intercultural communication skills. Students may also be encouraged to study abroad because both employers and institutions increasingly expect students to possess strong global competencies (Hunter, White, \& Godbey, 2006; Tarrant, 2010).

Many academic institutions include "global citizenship" as a specific learning outcome or student development competency for undergraduate students. Colleges and universities around the United States have made global 
citizenship a priority in student learning outcomes and mission statements, and study abroad programming is often considered to be a primary means for achieving this goal (Dolby, 2008; Rundstrom Williams, 2005). In response to the increasing demand for international opportunities, campuses have diversified their study abroad program models. On many campuses, students not only have opportunities to study abroad during academic year, semester, and short-term programs, they can also elect to participate in non-credit volunteer, internship, and work abroad programs. In addition to universityorganized international opportunities, students often have access to informal and recreational travel experiences through connections with student groups, religious organizations, friends, and family. Some students opt to participate in study abroad programs through their own institutions while others participate in study abroad opportunities through another institution or consortium of programs. Additionally, college students often travel abroad for recreational purposes and obtain cultural experiences that are not directly tied to an academic experience. In conjunction with the myriad international opportunities in which students participate, there are also fundamental differences in the cultural experiences offered by each (Engle $\&$ Engle, 2003).

This multi-institutional study attempts to discover whether different international activities in which students participate yield different outcomes for the development of students' global and intercultural competencies. The research question that guides this inquiry is as follows: controlling for other factors, is participation in these five types of international travel activities associated with different outcomes in students' development of global and intercultural competencies? The five international travel and study abroad measures analyzed include students' participation in a university study abroad program; study abroad program affiliated with another college or university; travel abroad for cross-cultural experiences or informal education; travel abroad for a service learning, volunteer, or work experience; and travel abroad for recreation. The five outcome variables used to measure students' development in global and intercultural competencies include self-reported gains in students' understanding of the complexities of global issues, ability to apply disciplinary knowledge in a global context, linguistic or cultural competency in another language, ability to work with people from other cultures, and comfort working with people from other cultures. This research paper contributes to the scholarly literature related to students' international and study abroad experiences because it examines the differential effects participation in several types of programs has on the development of students' global and intercultural competencies; as such, it provides student affairs practitioners, faculty members, and institutional decision-makers with insights into the types of 
international and study abroad experiences that provide students with the greatest opportunities for development and engagement.

\section{Literature Review}

\section{Conceptual Framework: Holistic Student Development and Engagement}

As described by Braskamp, Braskamp, and Merrill (2009), one of the objectives of higher education is to develop the whole student. Holistic student development is one of the foundational concepts of the student affairs profession (Braxton, 2009; Brown, 2011; Evans, Forney, Guido, Patton, \& Renn, 2010). This comprehensive approach to working with college students involves addressing the varied aspects of students' lives inside and outside of the classroom. From this perspective, student affairs practitioners (e.g., academic advisors; study abroad directors and staff; career counselors) and faculty members play vital roles in helping to develop and lead intentional curricular, co-curricular, and programmatic activities focused on several aspects of college student development, including the development of global learning and intercultural awareness (Hovland \& Schneider, 2011). Within this conceptual framework, activities and programs that are intentionally developed to foster deeper learning and engagement will lead to the development of outcomes that have a lasting impact on students -- even beyond college as students become global citizens (Haring-Smith, 2011; Kuh, Kinzie, Schuh, Whitt, \& Associates, 2005).

A central strategy for fostering holistic student development is to promote active student engagement in the collegiate experience; yet, engagement involves much more than the number of hours students devote to activities. According to Kuh (2009), student engagement represents both the effort students devote to activities that are linked to desired outcomes of college and the amount of support that institutions provide to foster students' participation. In order for student activities to have the most significant impact on student development and institutional outcomes (e.g., student persistence; increased graduation rates), leaders within academic institutions need to intentionally develop activities and provide students the structured support to engage fully in these activities, which can include global learning opportunities such as international student experiences.

Opportunities for academic and social engagement at the post-secondary level can take multiple forms (Wolf-Wendel, Ward, \& Kinzie, 2009), including high-impact educational practices that foster student development (Kuh, 2008). Examples of high-impact educational practices, as outlined by Kuh, 
include learning communities; first-year experience programs; common book experiences; service learning; diversity experiences; student-faculty research; senior capstone experiences; writing intensive courses; internships; and study abroad opportunities. In this study, we focus on study abroad as a high-impact educational activity, a type of student engagement, and as an intentional strategy to develop global competencies and awareness among college students. Within the conceptual framework of student engagement, it is hypothesized that international travel and study abroad activities that are deliberately and meaningfully developed to promote deeper student engagement and reflection will yield greater development outcomes in intercultural and global competencies in students.

Prior research has demonstrated that intentional study abroad activities yield strong influences on students' development of global and intercultural outcomes. According to Braskamp, Braskamp, and Merrill, (2009), "education abroad has become an increasingly important educational program (experience) in global learning and development, intercultural competence, intercultural maturity, and intercultural sensitivity of students" (p. 101). In the Braskamp et al. study, the authors opted to explore developmental processes from three domains: cognitive (cultural knowledge, global awareness), intrapersonal (identity, emotion), and interpersonal (behaviors, skills sets, and social responsibility). They also focused on human development and intercultural communication to encompass the idea of holistic student development; the two together shape the understanding of global learning and development in their model. Braskamp et al. concluded that study abroad is an effective educational experience for students, especially if the objective is to help students to develop holistically and globally, noting that "student engagement in education abroad experiences enhances global learning and development, which we argue should now become an important and even the core of holistic student development, a goal of almost every undergraduate college or university" (Braskamp, Braskamp, \& Merrill, 2009, p. 111)

The call for accountability in higher education in recent years has spurred growth in the number of studies seeking to validate the benefits of study abroad. The tendency of many studies is to explore high-impact educational practices, such as service learning and study abroad, through the lens of a specific program model (Anderson, Lawton, Rexeisen, \& Hubbard, 2006) or program duration (Dwyer, 2004). Large, multi-institutional studies that allow for a wider scope of inquiry or compare the effects of participation in different programs are still rare.

The three large, multi-institutional studies that have recently produced significant findings on study abroad learning outcomes are the Georgia 
Learning Outcomes of Students Studying Abroad Research Initiative (Sutton \& Rubin, 2004), the Georgetown Consortium Project (Vande Berg, ConnorLitman, \& Paige, 2009), and the Wabash National Study of Liberal Arts Education (Salisbury, 2011). The Wabash National Study of Liberal Arts Education study has provided data for multiple inquiries on study abroad outcomes across 17 universities, including Salisbury's (2011) research on the effect of study abroad on the development of intercultural competence among undergraduate college students. Each study offers important findings about the benefits of study abroad; however, none extend their reach to explore how different types of international experiences impact the development of global competencies in undergraduate students.

There are several smaller studies that substantiate the extended benefits of study abroad programs on student engagement; for example, Gonyea (2008) discovered that studying abroad had a positive impact on student development, and was also related to increased levels of engagement after the experience in the senior year, as students were more engaged after they returned from their study abroad experience. Study abroad programs can also be supplemented by similar high-impact educational practices, thus increasing the potential benefits for students; for example, Tarrant (2010) contended that service learning components should be intentionally integrated into the study abroad experience (Lardner \& Malnarich, 2008), especially to foster transformational learning experiences and the development of global citizenship. The way in which service learning or other high-impact measures are integrated into the structure of the study abroad experience is critical; for example, well-designed service learning components can be integrated into long and short-term abroad opportunities with positive results (Kehl \& Morris, 2007-2008). Wessel (2007) provided an overview of how service learning can be integrated into education abroad, using the example of sociology students studying in Mexico. Although service learning can contribute positively to the development of intercultural sensitivity, it does not necessarily do so, as there may be other experiences that help reach related objectives (Westrick, 2005).

Salisbury (2011) provided evidence that study abroad provides educational benefits regardless of students' pre-college backgrounds, educational aspirations, or college experience. Additional studies concur with Salisbury's finding; for example, Clarke, Flaherty, Wright, and McMillen (2009) discussed intercultural proficiencies that students ideally acquire via education abroad including the knowledge, skills, and attitudes/beliefs that enable people to work well with, respond effectively to, and be supportive of people in cross-cultural settings (p. 174). Included in the definition of intercultural proficiencies are global awareness; adeptness at intercultural 
communication; openness to diverse people; and intercultural sensitivity. Clarke et al. (2009) suggested that students who study abroad may have greater intercultural proficiency, increased openness to cultural diversity, and become more globally minded than their peers who remain back on campus. Students who engage in education abroad have greater self-perceptions of their global skills than students who do not participate in study abroad options; yet, little is known about whether specific types of study abroad activities elicit differences in global competencies and intercultural proficiencies among students.

In their initial paper outlining their multi-institutional research, Sutton and Rubin (2004) noted that "the field of international education is moving forward to confront the challenges of a data-driven, evidentiarybased articulation of the values gained from study abroad" (p. 76). This study is meant to provide data that will further the discussion by exploring how students develop global competencies through engagement in five types of international experiences and how their engagement can foster holistic student development.

\section{Research Questions}

The primary question leading this study is as follows: when controlling for a range of factors (including race, gender, social class, ACT scores, and academic engagement measures), what is the relationship between five different types of travel/study abroad participation and college students' development of global and intercultural competencies? The five travel and study abroad measures analyzed include experience in a university study abroad program; study abroad program affiliated with another college or university; travel abroad for cross-cultural experiences or informal education; travel abroad for a service learning, volunteer, or work experience; and travel abroad for recreation. Students' perceived development of global skills includes measures derived from students' self-assessment of their competencies before they arrived at college and their current competencies. Intercultural competence can be understood as the enhancement of appreciation of differences among cultures (Anderson et al., 2006). In this study, the five measures of students' global and intercultural competencies include the following: understanding the complexities of global issues, applying disciplinary knowledge in a global context, having linguistic and cultural competency in at least one language other than their own, working with people from other cultures, and working comfortably with people from other cultures. 


\section{Method}

\section{Instrument and Participants}

The Student Experience in the Research University (SERU) survey is based at the Center for Studies in Higher Education at the University of California Berkeley. The SERU survey sampling plan is a census scan of the undergraduate experience. All undergraduates enrolled spring 2010 who were also enrolled at the end of the prior term are included in this web-based questionnaire, with the majority of communication occurring by electronic mail.

The survey was administered to 287,498 undergraduate students across twelve large, public universities classified by the Carnegie Foundation as having very high research activity. The institutional level response rate for the SERU survey was $34.7 \%(n=99,810)$. Of the total participants who responded to the survey, $58 \%$ were female and $41.9 \%$ male. Additionally, the survey respondents were relatively diverse: $0.6 \%$ of respondents were American Indian or Alaskan Native; 3.5\% African American; 11.9\% Chicano or Latino; 32.2\% Asian, Filipino, or Pacific Islander; 43.5\% White; 5.0\% Unknown/ Other; and 3.3\% International.

\section{Variables}

In the SERU survey, each student answers a set of core questions and is randomly assigned one of four modules containing items focused specifically on a research theme. The core questions focus on time use, evaluation of a student's major, campus climate, and satisfaction, serving to highlight four thematic research areas: academic engagement, community and civic engagement, global knowledge and skills, and student life and development. Thirty percent of students were randomly assigned to complete a module that asked students about study abroad, national and global engagement, and other international academic experiences; therefore, our overall sample size is reduced but is relatively strengthened by the addition of the random assignment of students.

Within the randomly assigned module, students were also asked about their participation in study abroad or travel experiences. Table 1 demonstrates the frequency of students' responses when asked, "have you completed or are you now participating in the following activities?" More respondents (38.1\%) had traveled abroad for recreation as compared to other travel or study abroad activities. Students were also slightly more likely to travel abroad for a crosscultural experience or informal education as compared to more formal study abroad programs organized through the university. Some of the study/travel 
abroad experiences may not have been viewed by students as mutually exclusive from one another; therefore, some students may have identified with more than one category (e.g. students may have first traveled through a university study abroad program and then spent a week traveling for recreation before returning back to campus).

Table 1. Frequency of Travel or Study Abroad Experiences

\begin{tabular}{|c|c|c|c|c|}
\hline \multirow[b]{2}{*}{ Experiences } & \multicolumn{2}{|c|}{ Yes } & \multicolumn{2}{|c|}{ No } \\
\hline & $n$ & $\%$ & $n$ & $\%$ \\
\hline $\begin{array}{l}\text { University study abroad, including summer study } \\
\text { abroad }\end{array}$ & 2909 & 11.4 & 22512 & 88.6 \\
\hline $\begin{array}{l}\text { Study abroad program affiliated with another } \\
\text { college or university }\end{array}$ & 1416 & 5.6 & 23960 & 94.4 \\
\hline $\begin{array}{l}\text { Traveled abroad for a service learning, } \\
\text { volunteer, or work experience }\end{array}$ & 2704 & 10.7 & 22628 & 89.3 \\
\hline $\begin{array}{l}\text { Traveled abroad for cross-cultural experience or } \\
\text { informal education }\end{array}$ & 3982 & 15.7 & 21358 & 84.3 \\
\hline Traveled abroad for recreation & 9621 & 38.1 & 15659 & 61.9 \\
\hline
\end{tabular}

To gain an understanding of students' global competencies and intercultural skills, students were asked how they would rate their competency levels when they started at their university and their current ability level on a scale of one to six (very poor to excellent). The competencies we measured included current abilities in understanding the complexities of global issues, applying disciplinary knowledge in a global context, having linguistic and cultural competency in at least one language other than their own, working with people from other cultures, and working comfortably with people from other cultures. Gains in competencies were computed by subtracting students' initial ratings from their current rating of global competencies.

We controlled for several variables, including gender, race/ethnicity, academic abilities (as measured by students' performance on the ACT and SAT exams), and socioeconomic status (measured here by students' selfidentified social class). All demographic variables were dummy-coded (female $=1$, male $=0$; underrepresented minority $=1$, all other students $=0$; Asian $=$ 1 , all other students $=0$, low income $=1$, all other social classes $=0$; working class $=1$, all other social classes $=0$ ). Within the dummy-coded race/ethnicity variables, we excluded other/unknown and international students. We also measured students' precollege academic performance by converting students' SAT composite scores to ACT composite scores using ACT's concordance 
tables. In instances where students had both SAT and ACT scores, ACT scores were used.

We also controlled for additional college environmental and academic engagement factors that we surmised to affect students' acquisition of cultural competencies. To obtain these factors, we conducted a principal component analysis (PCA) on 27 items with oblique rotation (promax). The KaiserMeyer-Olkin measure verified the sampling adequacy for the analysis $(\mathrm{KMO}=$ .87). Bartlett's test of sphericity, $x^{2}(325)=953953.61, p<.001$, indicated that correlations between items were sufficiently large for PCA. An initial analysis was run to obtain eigenvalues for each component in the data; six components had an eigenvalue over Kaiser's criterion of one and explained $63.45 \%$ of the variance. Given the large sample size, Kaiser's criteria components, and the convergence of a scree plot that showed inflexions that justify retaining six components, the final analysis retained the following factors: campus climate, academic engagement, sense of belonging, research experience with faculty, research for credit, and classmate interactions. Table 2 shows the factor loadings after rotation in a pattern matrix, with factor loadings over .40 in bold. The factor scores were computed using the regression method and saved as standardized scores with a mean of zero and a standard deviation of one. The factors ranged in their reliability from Cronbach's $=.60$ to .92 , with the research experience factors having the lowest internal reliability. 


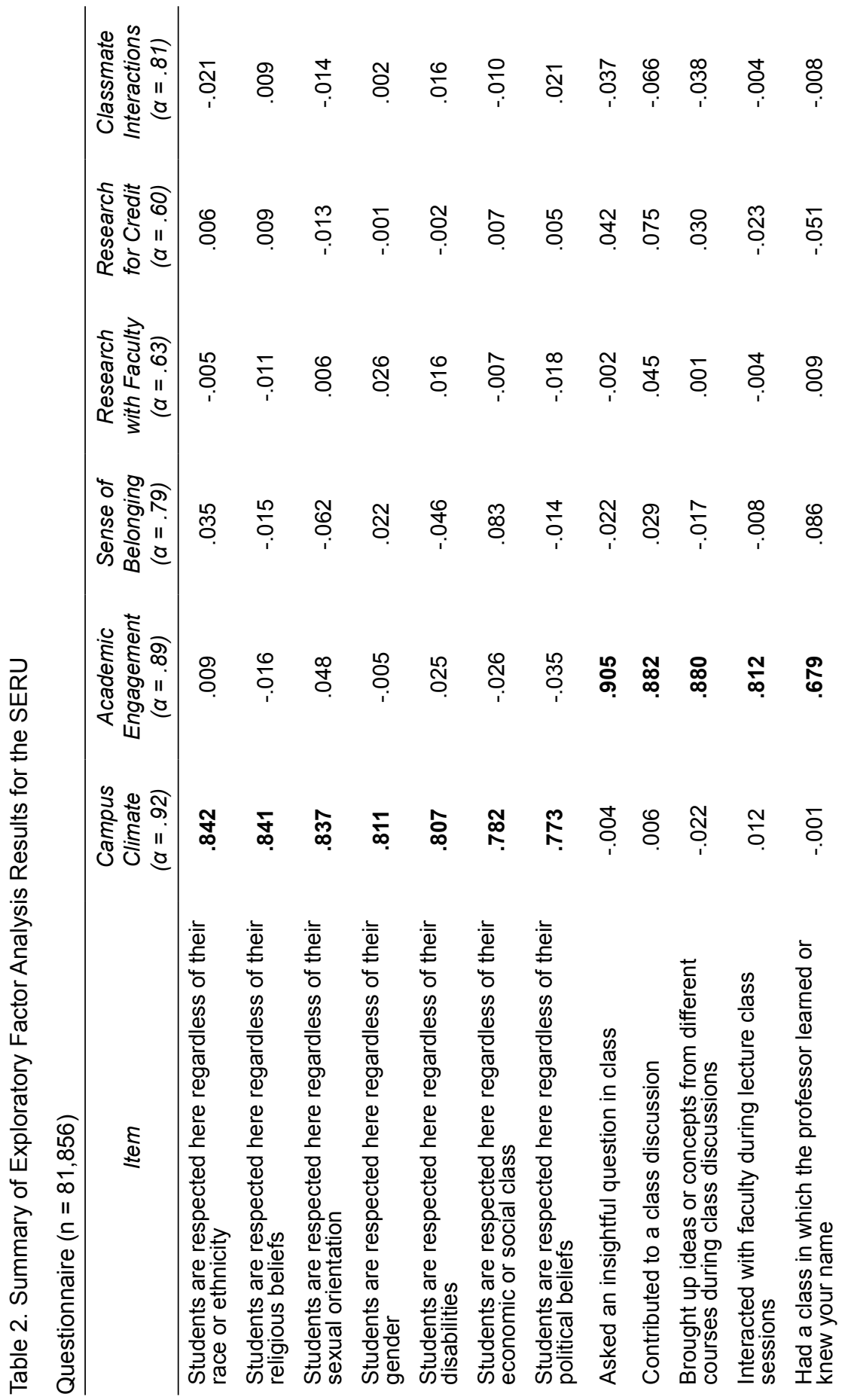




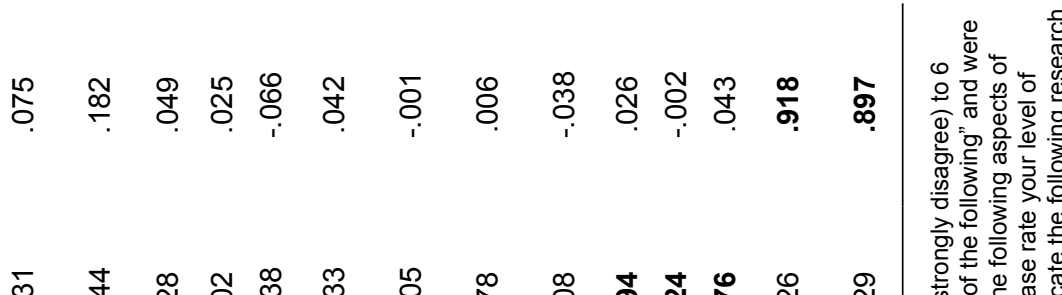

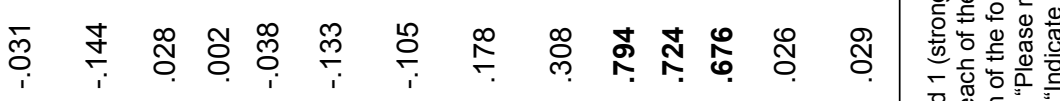

유 (1) 듀

ป ญ

๑ 음

ஸి 了궈워 잉잉

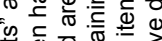
पू ह 焉

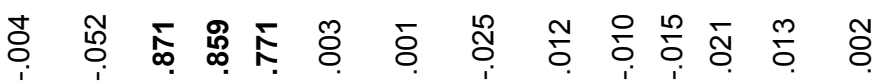

ஸृ

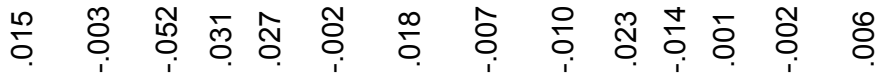

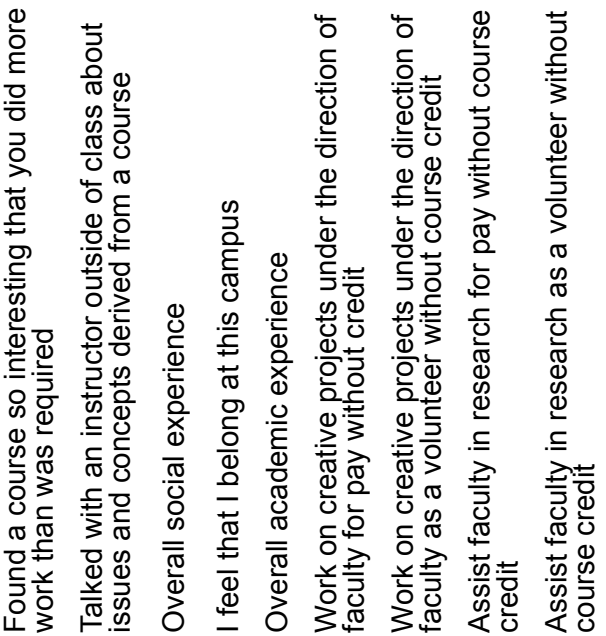

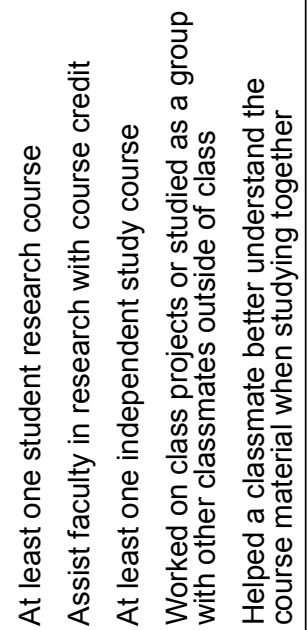

क

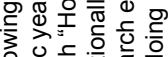
응.을 을 융 ᄂ

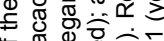
प。

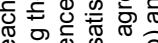
(든

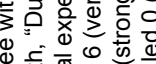

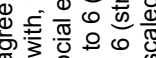

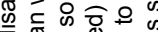

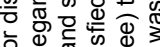

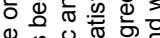
凹

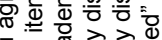

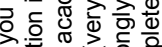

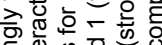

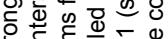
क.

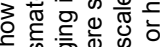

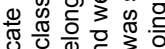

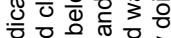

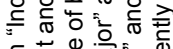
돓

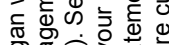

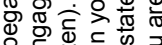

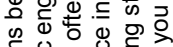

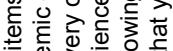

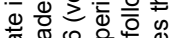

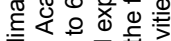

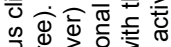

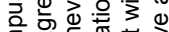
ह

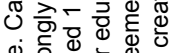

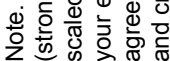




\section{Results}

\section{Relationship between Travel/Study Abroad Experiences and Global/Intercultural Outcomes}

In order to examine relationships between travel/study abroad experiences and students' global and intercultural competencies, we conducted linear regressions predicting each of the outcomes. In these regressions, we controlled for gender, race, social class, ACT scores, and the six factors derived in our factor analysis: academic engagement, campus climate, sense of belonging, research experiences for credit or with faculty, and classmate interactions (Table 3).

Our first model predicting students' development in understanding the complexities of global issues was statistically significant $(F(17,15118)=69.31$, $p<.001)$. This model suggests that participating in university-related study abroad, study abroad with another university, traveling abroad for service learning or work, and traveling abroad for recreation are positively associated with students' development in this area. Our second model predicting the development in students' ability to apply disciplinary knowledge in a global context was statistically significant, $F(17,14981)=72.74, p<.001)$. This model suggests that participation in all study/travel abroad opportunities except for traveling abroad for informal education is positively associated with students' development in the ability to apply disciplinary knowledge to a global context. Next, our model predicting linguistic and cultural competency in at least one language other than students' own language was found to be statistically significant $(F(17,15045)=49.59, p<.001)$. This model suggests that participation in all study/travel abroad opportunities except for traveling abroad for service is positively associated with students' development in linguistic and cultural competency in another language. Traveling abroad for recreation is negatively associated with students' development in linguistic/ cultural competency.

Our model predicting students' development in their ability to work with people from other cultures was statistically significant $(F(17,15090)=67.14$, $p<.001)$. This model suggests that university study abroad and traveling abroad for service are positively associated with students' development in students' ability to work with people from other cultures. Finally, our fifth model predicting students' development in their comfort working with people from other cultures was statistically significant $(F(17,15085==68)=55.77, p$ $<.001)$. This model suggests that study abroad and travel abroad for service are positively predictive of students' development in their comfort working with people from other cultures. Traveling abroad for recreation is negatively 
predictive of students' development in their comfort working with people from different cultures.

With regard to our sociodemographic control variables, we find that females reported higher development in linguistic/cultural competency in another language compared to males. Additionally, compared to their referent groups, Asian students reported larger gains in understanding the complexities of global issues, applying disciplinary knowledge in a global context, and in linguistic/cultural competency in another language and lower gains in comfort working with people from other cultures. Underrepresented minority students reported higher gains in all areas save for comfort working with people from other cultures. ACT scores were negatively predictive of all five competencies. Finally, low-income and working-class students reported higher gains in all five competency areas compared to their referent groups.

Students' academic engagement and sense of belonging on campus were positively predictive of all five competency areas. Classmate interactions were positively predictive of the ability and comfort working with people from other cultures and negatively predictive of the other three competency areas. Research with faculty was positively predictive of understanding the complexities of global issues while research for credit was negatively predictive of all areas save for linguistic/cultural competency. Finally, campus climate was negatively predictive of working with people from other cultures. 


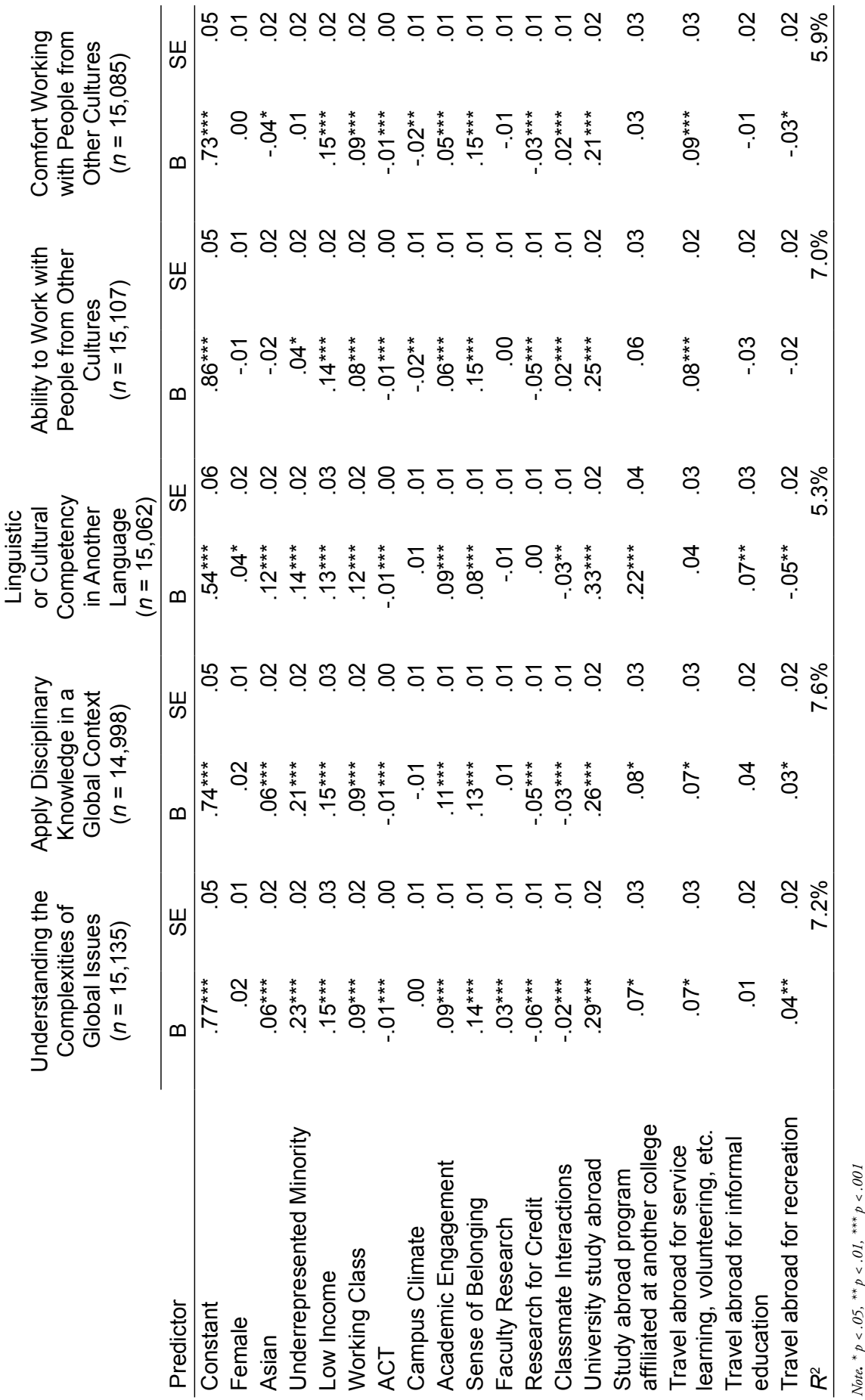




\section{Discussion}

The results of this study support Kuh's (2009) identification of study abroad as a high-impact practice for student engagement, which serves to deepen students' learning and is empirically linked to desired college outcomes, namely, global and intercultural competencies. Our results suggest that formal study abroad programs through the university or through another college/ university bring value-added components to students' intercultural and global competencies that generally meet or surpass the outcomes of other international travel opportunities. Reflecting back to our conceptual framework that focuses on holistic student development and engagement, international travel activities that are intentionally and thoughtfully designed to foster deeper engagement among students are positively associated with development in students' global and intercultural competencies. Compared to traveling abroad for recreational purposes or for informal education, formal study abroad opportunities are more significant in the overall increase in students' development in all five areas of intercultural and global competencies. We hypothesize that these observed differences are a direct result of the intentionality and structured planning behind well-designed study abroad programs; examples include: pre-departure workshops, embedded journal reflections, the opportunity to earn academic credit, increased interactions with faculty and classmates, post-trip reflection meetings, and more intense involvement in the foreign country.

Although cross-cultural and informal travel experiences did not have the overall impact of study abroad programming, these experiences did play an important part in the development of linguistic and cultural competence. One possible explanation may be that students who participate in informal educational experiences often do not have the structure and guided curriculum that a formal program possesses; instead students who participate in more informal experiences have the opportunity to meet host nationals through activities such as athletics, art, or music, and are thus able to build collaborative relationships. More research on this topic may help to understand why travel abroad for informal education has varied influences on students' cross-cultural interpersonal development.

Traveling abroad for service learning, volunteering, or work experience was significant to some aspects of the development of students' intercultural and global competencies, particularly in the areas of cross-cultural interpersonal skills. Our finding that traveling abroad for service learning, volunteer, or work experience is associated with students' intercultural and global development is consistent with previous research on the value of these experiences to the development of students' global competency; for example, Parker and Altman Dautoff (2007), who focused on the difference in learning outcomes between 
international service learning and study abroad activities, found that twice as many students cited a service learning project as the activity that increased their sense of connectedness to a wider world community than study abroad activities. Although study abroad opportunities prove to have a greater overall impact on students' global competency, service learning, volunteer, and work experiences are also beneficial to development. This result coincides with Kuh's (2008) inclusion of service learning, community-based learning as a highimpact educational practice.

Studying abroad through another college/university program was also often associated with higher increases in students' intercultural and global competencies. This suggests that the partnerships with other college/university study abroad programs that are already a common practice in study abroad offices may benefit students as much, if not more than, study abroad with the home campus. This finding supports previous studies that document intercultural learning outcomes achieved through program providers (Engle \& Engle, 2004; Dwyer, 2004). An additional explanation for the comparatively higher increase in competencies achieved through other college/university program participation may also be explained by the perceived additional challenges of studying with a different college/university or program provider; for example, when students choose to study abroad through their home university on a program designed by a university faculty member or their on-campus study abroad office, they may feel a connection to their home campus and have a sense of comfort in knowing details of the program, academic expectations, and the peer group with whom they will be studying. Engle and Engle (2004) noted that this desire for familiarity often results in a climate of comfort more often than one of challenge in study abroad programs. For students who participate in programs through providers or other colleges/universities, the myriad factors that go into their international experience, such as forming new friendship groups with students from around the U.S. and being unfamiliar with the academic expectations of the other university/college, may challenge participants to develop along a number of paths, spurring greater inclinations toward improving their global competencies.

The study also suggests the important influences of control variables that future researchers may wish to include in analysis and that practitioners may wish to consider in their practice; for example, students' academic engagement and sense of belonging on campus appears to positively influence the development of intercultural competencies. The data suggest that research experience negatively influences development of intercultural competencies, potentially signaling a missed opportunity, as cross-cultural, international, and global themes could be easily imbedded in many research courses or 
assignments.

Finally, our study indicates that international experiences across the five categories have the potential for significant development specifically in underrepresented, low-income, and working class students. The barriers to studying abroad for underrepresented and low-income students are well documented in Salisbury, Umbach, Paulsen, and Pascarella's (2009) study based on the Wabash National Study of Liberal Arts Education data; and despite efforts at diversifying study abroad participation, white students remain the majority at $77.8 \%$ (Institute of International Education, 2012). Potential barriers to students' participation in study abroad have been documented recently and, equipped with this information, student affairs practitioners have the opportunity to purposefully address them in the future (Lane, 2011). Encouraging more students from historically marginalized student groups to participate in study abroad experiences should be a priority for student affairs professionals, faculty members, and administrative leaders.

\section{Implications for Practice}

Student engagement is not only the "time and effort students devote to activities that are empirically linked to desired outcomes of college," but also incorporates "what institutions do to induce students to participate in these activities" (Kuh, 2009, p. 683). Student engagement at the research university may be different from small liberal arts institutions or community colleges; however, there are steps that educators on all campuses can take to create highimpact practices that encourage learning outcomes connected to global and intercultural competence.

\section{Build and strengthen partnerships}

Based on our findings that studying abroad through other colleges/ universities is associated with higher increases in global and intercultural competencies than studying abroad through the home institution, it is important that universities continue to build and strengthen their partnerships with other universities in the area of study abroad. Many study abroad offices already have partnerships with program providers and other universities to diversify the type of study abroad programs they offer to their students. Knowing the possible impact of studying through an outside provider rather than through the home campus should encourage international educators to collaborate and strengthen the partnerships that they already have and seek new and promising opportunities for collaboration.

Students will be encouraged to seek opportunities with university partners if their financial aid awards remain applicable and the academic credit 
earned is transferrable to their home institution. Administrative stakeholders will be more open to partnerships if it is financially viable. In order to offset the financial implications of sending students abroad through other colleges/ universities and program providers, creating partnerships that open faculty-led or home-institution programs to students from partner colleges/universities may yield benefits to students' development of global and intercultural competencies.

\section{Integrate service learning, volunteer, and work opportunities into study abroad programming}

Service learning, volunteer experiences, and work opportunities hold great potential to provide stimulating experiences when they are embedded in a study abroad program. Service learning and volunteer experiences are unique because they can be integrated into various study abroad program models. Students need not study abroad for an academic year to gain the benefits of service learning, but can reap rewards by becoming involved in the local community on short-term programs, which are increasingly popular (Lewis \& Neisenbaum, 2005; Parker \& Altman Dautoff, 2007).

Thoughtful integration of service learning, volunteer, or work opportunities in study abroad experiences may prove to have powerful effects in the areas of global and intercultural competencies and student engagement. The structure of the experience is critical; otherwise, students do not fully benefit from the service learning opportunity. Woolf (2008) recommended several key questions for student affairs and study abroad practitioners who intend to implement service learning into a study abroad program:

1. What do we want students to learn?

2. What do students want and need to learn?

3. How can these learning objectives be realized?

4. Can experience through service learning enhance the course, improve learning, and add academic value? (p. 24).

These questions can serve as a guide when designing service learning coursework as well as guided work and volunteer experiences abroad, which also hold promise in the area of holistic student development. Work and volunteer opportunities allow students to engage in learning through "real world" challenges while at the same time engaging in "collaborative interaction with people whose assumptions and life experiences are different from their own" (AAC\&U, 2007, p. 37).

Finally, Trooboff, Vande Berg, and Rayman (2007-2008) discovered that employers especially like to hire graduates that have participated in education 
abroad opportunities. More specifically, employers had a strong preference for programs that featured internships and service learning opportunities. Study abroad practitioners can help students articulate what they learned via education abroad using skills-based language (e.g., global competencies) that will resonate with prospective employers. International work, volunteer, and service learning opportunities may therefore create an opportunity for students to practice their cross-cultural skills and improve their understanding of global issues through concrete methods in a way that study abroad activities alone do not.

\section{Implement guided reflection throughout (and after) the study abroad experience}

Students experience emotional and intellectual challenge as a result of direct cultural encounters, and guided reflection upon their experiences encourages engagement with their peers, educators, and selves (Engle \& Engle, 2003). Guided reflection is cited as a way to provide students with the valuable opportunity to discuss what they are learning, reflect about it, and discern ways to apply their knowledge both within and outside the class (SmithParíolá \& Gòkè-Paríolá, 2006; Vande Berg, 2007). As we seek to encourage the development of global competency and student engagement, "experience integrated with rigorous and critical, constructive, and creative thinking may help students learn and develop even more holistically" (Braskamp, Braskamp, and Merrill, 2009, p. 113).

By integrating reflection prior to departure and during the term abroad, students are much more likely to remain engaged upon their return and make meaning of their experiences through the entire journey. How guided reflection is integrated into programming will vary by program model. For non-credit, volunteer programs students may debrief after each day in the field with a program leader. Faculty-led programs may be able to build in personal reflection into their course syllabus. On-site staff can prove to be important allies in guided reflection for students who are on programs through which they take a variety of courses and are involved with myriad activities in the community. When students travel for recreational purposes, their reflections can take the shape of a blog documenting their travels, which may serve as a way to market traveling abroad among students. Reflection allows students who travel abroad through any means to meaningfully share their experiences with fellow students in workshops or seminars, including those designed to teach students about important pre-departure health and safety information. Finally, the home study abroad office can offer ways for students to make meaning of their experience by having them participate in workshops upon 
return from the study abroad experience, often referred to as reorientation (Porter, 2011). The means through which guided reflection occurs will undoubtedly vary by institution and specific program; however, the need for this intentional reflection to maintain and encourage student engagement and development is clear.

\section{Limitations and Future Research}

There are a few limitations to this research project. First, the survey results were analyzed at only one institutional type, large, public research universities, thus limiting to an extent the generalizability of the findings. Inquiries using multiple institutions should continue to be conducted in the future, including a range of institutional types (e.g., public/private; research/ liberal arts colleges). The extent to which students interpreted different study abroad activities is also unknown, although we have attempted to address overlap in students' responses across the five study abroad categories. The study abroad experiences analyzed in this study are not completely isolated from each other; however, we understand that many study abroad experiences are not completely differentiated from other types of experiences and may indeed integrate a variety of planned (and spontaneous) beneficial opportunities for students.

This analysis relies upon students' self-reported participation in study and travel abroad activities, as opposed to institutionally-gathered data (e.g. records or transcripts verifying study abroad). While this may be viewed as a limitation, many institutions do not collect data related to students' participation in travel abroad for recreation, for informal or cross-cultural purposes, or for service learning/volunteering, so it would not have been possible to collect institutional records on these diverse and important experiences.

Additionally, while every analysis of survey data is somewhat limited by factors including nonresponse bias, the random assignment of the module questions attempts to strengthen the results. The amount of variability accounted for in each of the global and intercultural competencies is relatively low; this suggests that several other factors not included in our regressions also contribute to students' competencies. As a result, we recommend that future studies explore the effects of such impacts as taking internationallythemed courses, enrollment in international certificates of study, befriending international students, or the pursuit of internationally-themed student organizations and how those types of activities may also contribute to the development of students' global competencies.

Finally, we advocate for qualitative research to understand how each of the study abroad activities explored in our study can lead to different 
outcomes. Learning more about the ways in which students' study abroad and international travel experiences contribute to their overall growth and development is key toward unveiling all of the benefits study abroad offers to college campuses as a whole. We recommend qualitative interviews or other interpretive research approaches with students who have completed education abroad opportunities (Creswell, 2007). Learning about the effects of study abroad post-college through longitudinal studies, such as Paige, Fry, Stallman, Josic, and Jon's (2009) SAGE study, will also help to advance our knowledge of how students use their global competencies in an increasingly global workplace.

As more college students seek out opportunities for education abroad, it is imperative to learn more about students' experiences. Ideally, more college students will take advantage of well-designed cross-cultural educational opportunities. There will likely continue to be a growing emphasis and value placed on strong intercultural communication and global competencies, especially by prospective employers of new graduates. Study abroad practitioners, faculty members, and administrators can help foster these skills by implementing reflection into the study abroad curriculum as well as including structured service learning, volunteer work, internship, or some form of guided work experience during the education abroad opportunity.

\section{References}

Anderson, P. H., Lawton, L., Rexeisen, R. J., \& Hubbard, A.C. (2006). Short-term study abroad and intercultural sensitivity: A pilot study. International Journal of Intercultural Relations, 30, 457-469.

Association of American Colleges and Universities (AAC\&U). (2007). College learning for the new global century: A report from the National Leadership Council for Liberal Education and America's Promise. Washington, DC.

Braskamp, L.A., Braskamp, D.C., Merrill, K.C. (2009). Assessing progress in global learning and development of students with education abroad experiences. Frontiers: The Interdisciplinary Journal of Study Abroad, 13, 101-118.

Braxton, J. M. (2009). Understanding the development of the whole person. Journal of College Student Development, 50, 573-575.

Brown, R. D. (2011, Spring). Educating the whole student: Our heritage and future challenges. ACPA Developments 9(1). Retrieved from http:// www2.myacpa.org/publications/developments.

Clarke, I., Flaherty, T. B., Wright, N. D., \& McMillen, R. M. (2009). Student intercultural proficiency from study abroad programs. Journal of Marketing Education, 31, 173-181. 
Creswell, J. W. (2007). Qualitative inquiry and research design: Choosing among five approaches (2 ed.). Thousand Oaks, CA: Sage.

Dolby, N. (2008). Global citizenship and study abroad: A comparative study of American and Australian undergraduates. Frontiers: The Interdisciplinary Journal of Study Abroad, 17, 51-67

Dwyer, M.M. (2004). More is better: The impact of study abroad program duration. Frontiers: The Interdisciplinary Journal of Study Abroad, 10, 151-164.

Engle, L., \& Engle, J. (2003). Study abroad levels: Toward a classification of program types. Frontiers: The Interdisciplinary Journal of Study Abroad, 9, $1-20$.

Engle, L., \& Engle, J. (2004). Assessing language acquisition and intercultural sensitivity development in relation to study abroad program design. Frontiers: The Interdisciplinary Journal of Study Abroad, 10, 219-236.

Evans, N. J., Forney, D. S., Guido, F. M., Patton, L. D., \& Renn, K. A. (2010). Student development in college: Theory, research, and practice (2nd ed.). San Francisco, CA: Jossey-Bass.

Gonyea, R.M. (2008, November). The impact of study abroad on senior year engagement. Paper presented at the annual meeting of the Association for the Study of Higher Education, Jacksonville, FL.

Haring-Smith, T. (2011). The Magellan Project: Developing global citizens through independent study abroad. About Campus, 16(5), 9-12.

Hovland, K., \& Schneider, C. G. (2011). Deepening the connections: Liberal education and global learning in college. About Campus, 16(5), $2-8$.

Hunter, B., White, G. P., \& Godbey, G. C. (2006). What does it mean to be globally competent? Journal of Studies in International Education, 10, 267-285.

Institute of International Education (2012). Open doors report. Retrieved from www.iie.org/opendoors.

Kehl, K., \& Morris, J. (2007-2008). Differences in global-mindedness between short-term and semester-long study abroad participants. Frontiers: The Interdisciplinary Journal of Study Abroad, 15, 67-79.

Kuh, G. D. (2008). High-impact educational practices: What they are, who has access to them, and why they matter. Washington, DC: Association of American Colleges and Universities.

Kuh, G.D. (2009). What student affairs professionals need to know about student engagement. Journal of College Student Development, 50, 683706. 
Kuh, G. D., Kinzie, J., Schuh, J. H., \& Whitt, E. J. \& Associates (2005). Student success in college: Creating conditions that matter. San Francisco, CA: Jossey-Bass.

Lane, J. E. (2011, Winter). Students studying abroad: Exploring barriers to participation, ACPA Developments, 9(4). Retrieved from http://www2. myacpa.org/publications/developments.

Lardner, E., \& Malnarich, G. (2008). A new era in learning: Why the pedagogy of intentional integration matters. Change, 40(4), 30-37.

Lewis, T.L. \& Niesenbaum, R.A. (2005). Extending the stay: Using community-based research and service learning to enhance short-term study abroad. Journal of Studies in International Education, 9, 251-264.

Paige, R.M., Fry, G., Stallman, E.M., Josic, J. \& Jon, J. (2009). Study abroad for global engagement: the long term impact of mobility experiences. Intercultural Education. 20, S29-S44.

Parker, B. \& Altman Dautoff, D. (2007). Service-learning and study abroad: Synergistic learning opportunities. Michigan Journal of Community Service Learning, 13(7), 40-53.

Porter, M. C. (2011). Assessing alternative breaks: Moving beyond sleeping on floors and pass-the-candle reflection. About Campus, 16(5), 21-24.

Rundstrom Williams, T. (2005). Exploring the impact of study abroad on students' intercultural communication skills: Adaptability and sensitivity. Journal of Studies in International Education, 9, 356-371.

Salisbury, M. H. (2011). The effect of study abroad on intercultural competence among undergraduate college students. (Unpublished doctoral dissertation). University of Iowa, Iowa City, IA. Retrieved from http:// ir.uiowa.edu/etd/1073.

Salisbury, M.H., Umbach, P.D., Paulsen, M.B., \& Pascarella, E.T. (2009) Going global:

Understanding the choice process of the intent to study abroad. Research in Higher Education, 50, 119-143.

Smith-Paríolá, J., \& Gòkè-Paríolá, A. (2006). Expanding the parameters of service learning: A case study. Journal of Studies in International Education, 10, 71-86.

Sutton, R.C. \& Rubin, D.L. (2004). The GLOSSARI project: Initial findings from a system-wide research initiative on study abroad learning outcomes. Frontiers: The Interdisciplinary Journal of Study Abroad, 10, 65-82.

Tarrant, M. A. (2010). A conceptual framework for exploring the role of studies abroad in nurturing global citizenship. Journal of Studies in International Education, 14, 433-451. 
Trooboff, S., Vande Berg, M., \& Rayman, J. (2007-2008). Employer attitudes toward study abroad. Frontiers: The Interdisciplinary Journal of Study Abroad, 15, 17-33.

Vande Berg, M. (2007). Intervening in the learning of U.S. students abroad. Journal of Studies in International Education, 11, 392-399.

Vande Berg, M., Connor-Linton, J., \& Paige, M. R. (2009). The Georgetown Consortium Project: Interventions for student learning abroad. Frontiers: The Interdisciplinary Journal of Study Abroad, 18, 1-75.

Wessel, N. (2007). Integrating service learning into the study abroad program: U.S. Sociology students in Mexico. Journal of Studies in International Education, 11, 73-89.

Westrick, J. M. (2005). Phenomenology and meaning making: Student voices and understandings of cultural difference. Journal of Studies in International Education, 9, 105-120.

Wolf-Wendel, L., Ward, K., \& Kinzie, J. (2009). A tangled web of terms: The overlap and unique contribution of involvement, engagement, and integration to understanding college student success. Journal of College Student Development, 50, 407-428.

Woolf, M. (2008). "Not serious stuff? Service-learning in context: An international perspective. Frontiers: The Interdisciplinary Journal of Study Abroad, 17, 21-32. 